\title{
Output Characteristics of GaAs Cell Irradiated by Laser
}

\author{
Xiaowei LI* \\ Department of Physics and Electronic Information Engineering, Chifeng University, Chifeng 024000, China \\ *Corresponding author: Xiaowei LI_ E-mail:nmglxw2000@126.com
}

\begin{abstract}
The output characteristics of GaAs cell are keys for the laser wireless power transmission system design. The measurement platform for the output characteristics of GaAs cell is established by single-junction GaAs cell and $1064 \mathrm{~nm}$ fiber laser. The influence rules of laser power and temperature on the short-circuit current, open-circuit voltage, peak power, fill factor, and conversion efficiency are measured. The measurement results show that the conversion efficiency firstly increases and then decreases with an increase in laser power, and reaches a maximum of $54.5 \%$ at the laser power of $0.405 \mathrm{~W}$, whereas the conversion efficiency decreases with an increase in temperature, and decreases slowly with an increase in laser power.
\end{abstract}

Keywords: Laser; GaAs cell; peak power; conversion efficiency; wireless power transmission

Citation: Xiaowei LI, “Output Characteristics of GaAs Cell Irradiated by Laser,” Photonic Sensors, 2018, 8(3): $228-233$.

\section{Introduction}

In recent years, with the development of photovoltaic technology, high-power laser technology, and the increase of wireless power transmission requirements, the laser wireless power transmission technology has gradually gained people's attention. The laser has the advantages of good monochromaticity, good directivity, and energy concentration. It can realize long-distance and high-power wireless power transmission with a small receiver area. Therefore, it has a wide range of application prospects in the energy supply in many fields such as space detectors, near space vehicles, and unmanned aircrafts $[1,2]$. The photovoltaic cell is the basic unit of laser wireless power transmission system, and its performance directly affects the working state of the system. Therefore, it is very important to accurately grasp the performance parameters of photovoltaic cell for the design of laser wireless power transmission system. The semiconductor laser has high electro-optical conversion efficiency and low cost. In addition, the silicon cell has better spectral response to $808 \mathrm{~nm}$ laser. At present, the research on the performance of laser-irradiated photovoltaic cell is mostly focused on the performance of $808 \mathrm{~nm}$ semiconductor laser irradiated silicon cell [3, 4]. On the one hand, $808 \mathrm{~nm}$ semiconductor laser has large divergence angles, low power, and severe atmospheric transmission attenuation, which has limitations in laser wireless power transmission. On the other hand, the GaAs cell has the advantages of large optical absorption coefficient, high photoelectric conversion efficiency, strong radiation resistance, and high temperature resistance. Study on the output characteristics of GaAs cell irradiated by laser is of great significance for the exploration of laser

Received: 7 April 2018 / Revised: 12 June 2018

(C) The Author(s) 2018. This article is published with open access at Springerlink.com

DOI: $10.1007 / \mathrm{s} 13320-018-0503-\mathrm{z}$

Article type: Regular 
wireless power transmission. In addition, most of the previous researches focused on the relationship between the output characteristics of photovoltaic cell and the laser power [5-8], whereas the effect of temperature on the performance of photovoltaic cell is less studied. In reality, due to the high laser power density, the photovoltaic cell will produce a significant temperature rise, resulting in a decrease in the performance of photovoltaic cell [9-12]. Therefore, the relationship between the output characteristics of photovoltaic cell and the temperature is also an important aspect that should be considered. This paper focuses on single-junction GaAs cell and $1064 \mathrm{~nm}$ fiber laser. The measurement platform for the output characteristics of GaAs cell is established, the influence rules of laser power and temperature on the short-circuit current, open-circuit voltage, peak power, fill factor, and conversion efficiency are measured, which can provide technical support for laser wireless power transmission system design.

\section{Method design}

The system is mainly divided into two parts: the laser emitting end and the photovoltaic cell receiving end. The laser emitting end includes a laser, a beam expander, an aperture, and a half mirror. The photovoltaic cell receiving end includes a GaAs cell, a temperature control module, a laser power meter, and an I-V analyzer. The laser is firstly expanded by the beam expander and then divided into two parts by the half mirror. One part irradiates the GaAs cell, and the other part irradiates the laser power meter. Different from the design requirements of traditional photovoltaic cell through multi-junction structures, the energy carrier used in this paper is a single-frequency laser, and the single-junction GaAs cell can meet the requirements. By changing the components of GaAs cell and using $\mathrm{InP}$ as the substrate, the wavelength at the peak of spectral response curve is adjusted to the wavelength of incident laser, and the energy conversion efficiency can be optimized. By adjusting the beam expander and aperture, it is possible to achieve a continuous adjustment of the spot size on the surface of GaAs cell sample, so that the spot size is slightly larger than the sample size. Besides measuring the value, the laser power meter monitors the stability of laser power. The GaAs cell is attached to the temperature control module. The temperature of GaAs cell is controlled by adjusting the current. The short-circuit current, open-circuit voltage, and peak power can be directly collected through the I-V analyzer, and the fill factor and conversion efficiency can be indirectly calculated as

$$
F F=\frac{V_{\mathrm{mp}} I_{\mathrm{mp}}}{V_{\mathrm{oc}} I_{\mathrm{sc}}}
$$

where $V_{\mathrm{mp}}$ and $I_{\mathrm{mp}}$ are the corresponding voltage and current for the peak power, respectively, and $V_{\mathrm{oc}}$ and $I_{\mathrm{sc}}$ are the open-circuit voltage and short-circuit current, respectively.

The conversion efficiency is as

$$
\eta=\frac{P_{\mathrm{mp}}}{P_{\text {in }}}
$$

where $P_{\mathrm{mp}}$ is the peak power, and $P_{\mathrm{in}}$ is the incident power.

\section{System setup}

The system setup is shown in Fig. 1. The parameters of the components are shown in Table 1.

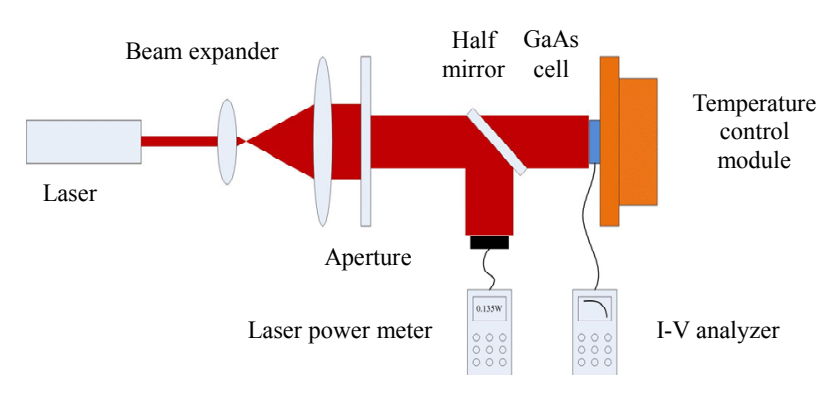

Fig. 1 System setup. 
Table 1 Parameters of the components.

\begin{tabular}{|c|c|c|c|}
\hline System & & & Parameter \\
\hline \multirow{6}{*}{$\begin{array}{c}\text { Laser } \\
\text { emitting end }\end{array}$} & \multicolumn{2}{|c|}{ Laser } & $\begin{array}{c}\text { Type: fiber laser } \\
\text { Wavelength: } 1064 \mathrm{~nm}\end{array}$ \\
\hline & \multirow{3}{*}{ Beam expander } & \multirow[b]{2}{*}{ Convex lens 1} & Diameter: $25 \mathrm{~mm}$ \\
\hline & & & Focal length: $50 \mathrm{~mm}$ \\
\hline & & Convex lens 2 & $\begin{array}{l}\text { Diameter: } 25 \mathrm{~mm} \\
\text { Focal length: } 150 \mathrm{~mm}\end{array}$ \\
\hline & \multicolumn{2}{|c|}{ Aperture } & Adjustment range: $2 \mathrm{~mm}-50 \mathrm{~mm}$ \\
\hline & \multicolumn{2}{|c|}{ Half mirror } & Diameter: $25 \mathrm{~mm}$ \\
\hline \multirow{4}{*}{$\begin{array}{l}\text { Photovoltaic cell } \\
\text { receiving end }\end{array}$} & \multicolumn{2}{|c|}{ GaAs cell } & $\begin{array}{l}\text { Type: single-junction } \\
\text { Size: } 10 \mathrm{~mm} \times 10 \mathrm{~mm}\end{array}$ \\
\hline & Temperatu & 1 module & Accuracy: $0.1{ }^{\circ} \mathrm{C}$ \\
\hline & \multicolumn{2}{|c|}{ Laser power meter } & $\begin{array}{c}\text { Measurement range: } 0 \mathrm{~W}-30 \mathrm{~W} \\
\text { Probe diameter: } 30 \mathrm{~mm}\end{array}$ \\
\hline & \multicolumn{2}{|c|}{ I-V analyzer } & $\begin{array}{l}\text { DC voltage resolution: } 1 \mathrm{mV} \\
\text { DC current resolution: } 0.1 \mathrm{~mA}\end{array}$ \\
\hline
\end{tabular}

\section{Results}

The short-circuit current, open-circuit voltage, peak power, fill factor, and conversion efficiency of GaAs cell versus incident power at $25^{\circ} \mathrm{C}$ are shown in Fig. 2. It can be seen that the short-circuit current changes linearly with the laser power, the open-circuit voltage and peak power changes logarithmically with the laser power, the fill factor and conversion efficiency show a single peak curve with the change of laser power, and the change trends of the two are the same. On the left side of the peak, the fill factor and conversion efficiency increase with an increase in laser power. On the right side of the peak, the fill factor and conversion efficiency decrease with an increase in laser power. When the laser power is $0.405 \mathrm{~W}$, the fill factor and conversion efficiency reach a maximum of about 0.91 and $54.5 \%$. This is because there is recombination radiation in the GaAs cell. As the photon energy emitted by the recombination radiation is generally larger than the band gap of GaAs cell, the reabsorption process exists, and only the net recombination contributes to the conversion efficiency. When the laser power is low, the proportion of recombination radiation in total incident radiation is larger, and the conversion efficiency is low. With an increase in laser power, the proportion of recombination radiation decreases, and the conversion efficiency increases. When the recombination radiation ratio drops to 0 , the conversion efficiency reaches a maximum value. In addition, the thermal resistance effect of GaAs cell under high laser power becomes intense. Therefore, the conversion efficiency begins to decrease with an increase in laser power.

The temperatures of GaAs cell versus time under different laser power irradiations are shown in Fig.3. It can be seen that with the continuous irradiation of laser, the temperature of GaAs cell gradually increases, and the increase range is related to the laser power. When the laser powers are $0.135 \mathrm{~W}$, $0.405 \mathrm{~W}, 0.675 \mathrm{~W}$, and $1.35 \mathrm{~W}$, the maximum increases are $1.62{ }^{\circ} \mathrm{C}, 3.78{ }^{\circ} \mathrm{C}, 6.85{ }^{\circ} \mathrm{C}$, and $18.19^{\circ} \mathrm{C}$, respectively. This is because the larger the laser power is, the more energy is absorbed by GaAs cell, the more heat energy is converted, and the greater the temperature increases. When stopping the irradiation of laser after 60 seconds, the temperature of GaAs cell begins to decrease. In the initial stage, the temperature decreases rapidly, and then the temperature decreases slowly and gradually tends to a stable temperature, which is still higher than the initial temperature in a short time. This is due to the fact that the thermal diffusion of GaAs cell is mainly through infrared radiation and is proportional to the fourth power of temperature. In the initial stage, the 
temperature of GaAs cell is relatively high, the infrared radiation is strong, and the temperature

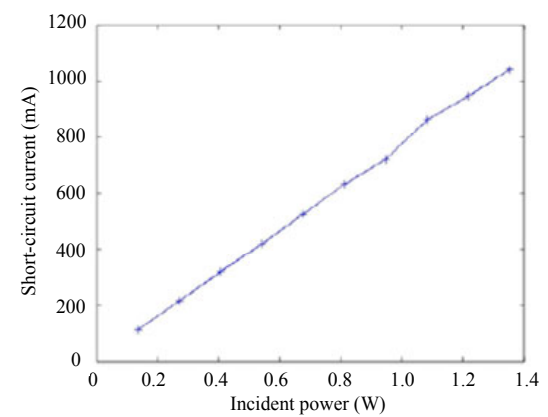

(a)

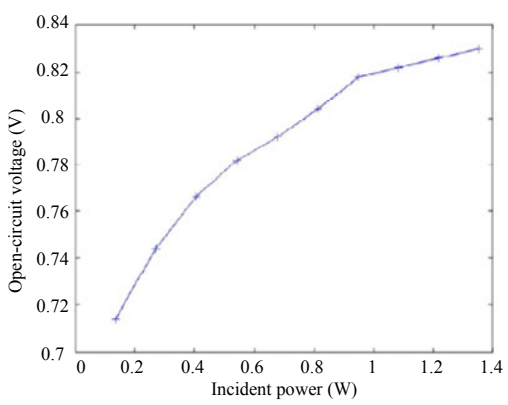

(c)

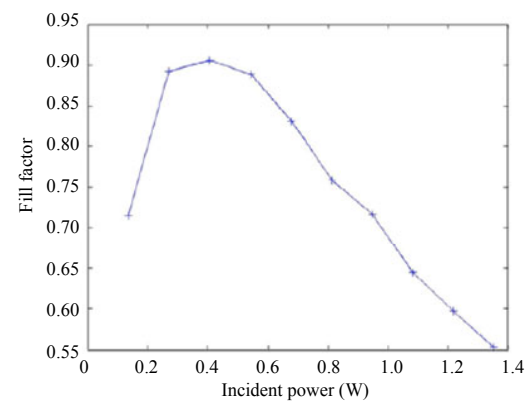

(d) decreases rapidly. Then, the infrared radiation is weakened, and the temperature decreases slowly.

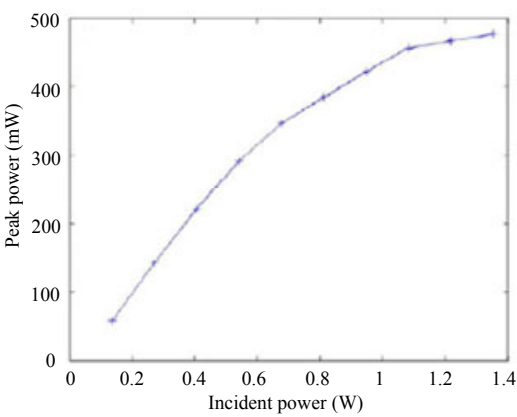

(b)

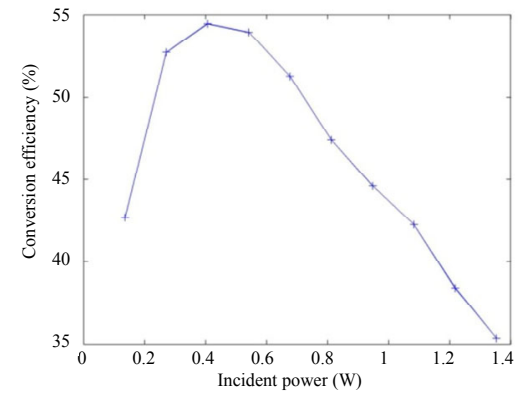

(e)

Fig. 2 Output characteristics of GaAs cell versus incident power: (a) short-circuit current, (b) open-circuit voltage, (c) peak power, (d) fill factor, and (e) conversion efficiency.

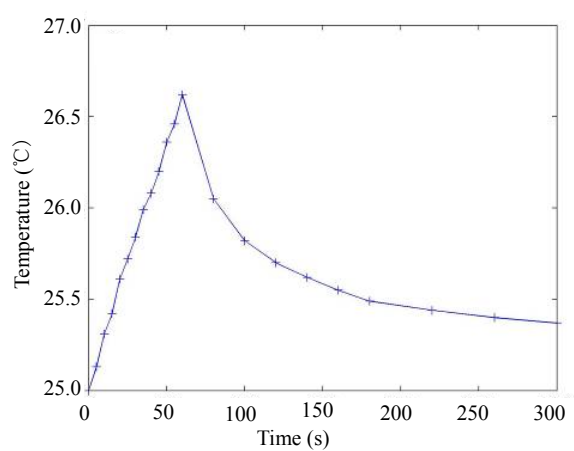

(a)

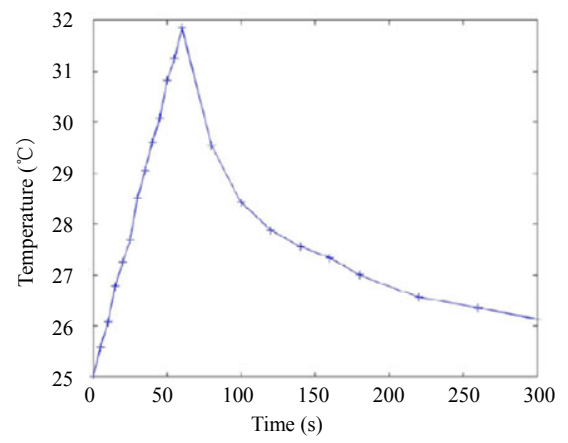

(c)

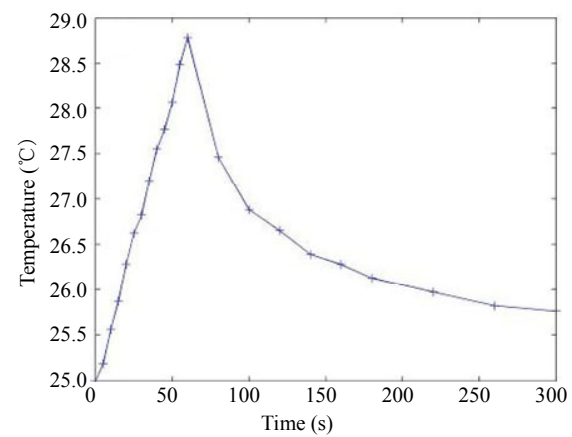

(b)

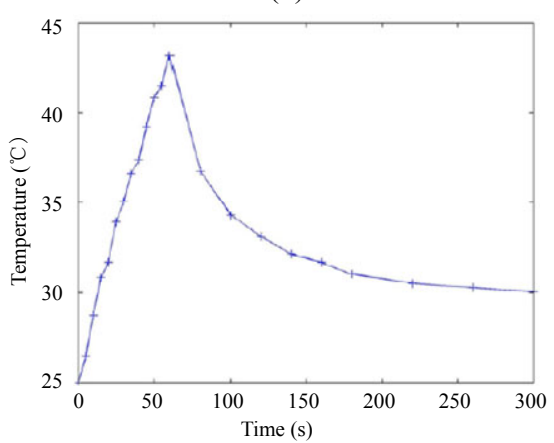

(d)

Fig. 3 Temperature of GaAs cell versus time: (a) incident power $0.135 \mathrm{~W}$, (b) incident power $0.405 \mathrm{~W}$, (c) incident power $0.675 \mathrm{~W}$, and (d) incident power $1.35 \mathrm{~W}$. 
The influence of temperature on the short-circuit current and fill factor is negligible. The open-circuit voltage, peak power, and conversion efficiency versus temperature under different laser power irradiations are shown in Fig. 4. It can be seen that the open-circuit voltage decreases with an increase in temperature, and the decrease rate decreases with an increase in laser power. This is because the increase of temperature makes the band gap of GaAs cell narrower, and causes an increase in the depletion layer recombination rate, and then leads to a decrease in open-circuit voltage. With an increase in laser power and the luminous flux, the density of

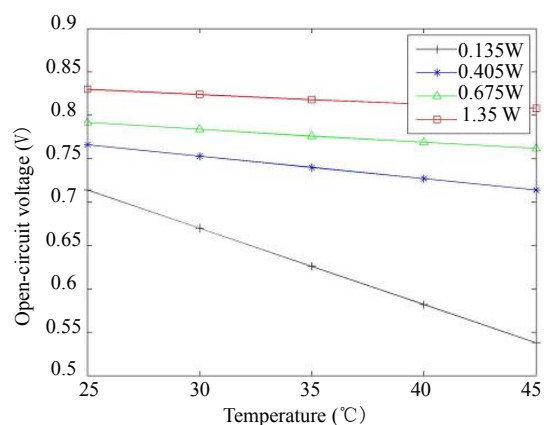

(a)

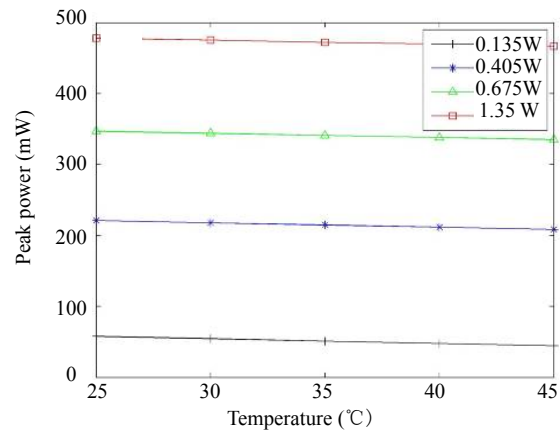

(b)

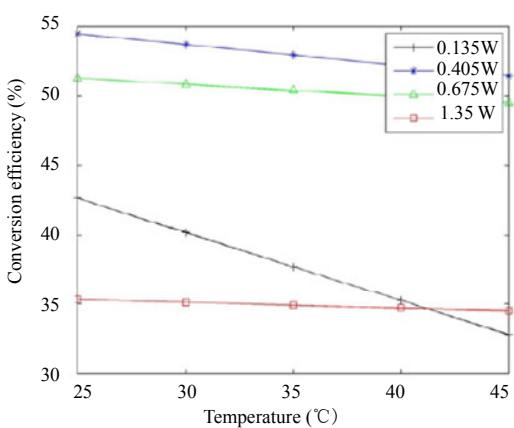

(c)

Fig. 4 Output characteristics of GaAs cell versus temperature: (a) open-circuit voltage, (b) peak power, and (c) conversion efficiency.

\section{Discussion and conclusions}

The output characteristics of single-junction GaAs cell irradiated by $1064 \mathrm{~nm}$ fiber laser is studied, and the relationship between the output characteristics and the laser power and temperature is analyzed. It shows that the conversion efficiency of GaAs cell is high with the matching wavelength and the power of laser irradiation, which is suitable for laser wireless power transmission applications. The conversion efficiency shows a single peak curve with the change of laser power. With the continuous irradiation of laser, the temperature of GaAs cell gradually increases, which leads to a decrease in conversion efficiency. Therefore, appropriate temperature control measures should be taken to reduce the influence of temperature.

The work can be an important supplement to the existing research, which is mostly focused on the minority carriers and short-circuit current increase, which makes the influence of dark saturation current smaller than the positive current on the open-circuit voltage. The peak power and conversion efficiency decreases with an increase in temperature, and the decrease rate decreases with an increase in laser power. This indicates that the decrease in peak power and conversion efficiency is mainly due to a decrease in open-circuit voltage. When stopping the irradiation of laser, the output characteristics of GaAs cell will gradually recover with a decrease in temperature. 
Science Foundation of China (Grant No. 11647096) and the Inner Mongolia Natural Science Foundation (Grant No. 2016BS0102).

Open Access This article is distributed under the terms of the Creative Commons Attribution 4.0 International License (http://creativecommons.org/licenses/by/4.0/), which permits unrestricted use, distribution, and reproduction in any medium, provided you give appropriate credit to the original author(s) and the source, provide a link to the Creative Commons license, and indicate if changes were made.

\section{References}

[1] N. Kawashima, K. Takeda, and K. Yabe, "Application of the laser energy transmission technology to drive a small airplane," Chinese Optics Letters, 2007, 5(s1): 109-110.

[2] D. E. Becker, R. Chiang, C. Keys, A. W. Lyjak, J. A. Nees, and M. D. Starch, "Photovoltaic concentrator based power beaming for space elevator application," in Proceeding of the 6th International Symposium on Beamed Energy Propulsion, Scottsdale, USA, 2010, pp. 271-281.

[3] H. M. Jiang, X. A. Cheng, and W. Y. Li, "Response of silicon p-n junction solar cell to DF laser irradiation," High Power Laser and Particle Beams, 2003, 15(1): 21-24.

[3] D. D. Qiu, R. Wang, X .A. Cheng, and H. S. Jin, " $\mathrm{CO}_{2} \mathrm{CW}$ laser irradiation effect on monocrystalline silicon cells," High Power Laser and Particle
Beams, 2011, 23(6): 1671-1674.

[4] H. Yugami, Y. Kanamori, H. Arashi, and M. Niino, "Field experiment of laser energy transmission and laser to electric conversion," in Proceeding of the Intersociety Energy Conversion Engineering Conference, Honolulu, USA, 1997, pp. 625-630.

[5] T. He, S. H. Yang, H. Y. Zhang, C. G. Zhao, P. Xu, J. Y. Hao, et al., "Experiment of space laser energy transmission and conversion with high efficiency," Chinese Journal of Lasers, 2013, 40(3): 0317001-1-0317001-6.

[6] L. Qiao and Y. N. Yang, "Experimental research of laser wireless power transmission efficiency," Laser Technology, 2014, 38(5): 590-594.

[8] F. Khan, S. N. Singh, and M. Husanin,, "Effect of illumination intensity on cell parameters of a silicon solar cell," Solar Energy Material \& Solar Cells, 2010, 94(9): 1473-1476.

[9] X. J. Li, Y. W. Yang, B. B. Li, and D. L. Zhang, "Effect of thermal radiation in space on photovoltaic cell," Laser \& Infrared, 2015, 45(12): 1444-1449.

[10] Y. C. Zhang, "Theoretical and experimental research on efficiency improvements of laser cells," $\mathrm{Ph}$. D. dissertation, Beijing Institute of Technology, Beijing, China, 2016.

[11] W. S. Hua, X. G. Liu, and D. M. Zhang, "Output characteristics of single-junction GaAs photovoltaic cell irradiated by laser," Laser \& Infrared, 2016, 46(12): 1463-1466.

[12] P. Singh and N. M. Ravindra, "Temperature dependence of solar cell performance-an analysis," Solar Energy Material \& Solar Cells, 2012, 101(12): 36-45. 